\title{
Quality assessment of individual case safety reports in pharmacovigilance in Burkina Faso
}

\author{
Nazaire Roamba ${ }^{1, *}$, Emile Windné Ouedraogo ${ }^{3}$ and Estelle Noella Hoho Youl ${ }^{2,4}$ \\ ${ }^{1}$ University Hospital center of Souro Sanou (Bobo Dioulasso, Burkina Faso) \\ ${ }^{2}$ University Hospital center of Yalgado Ouedraogo (Ouagadougou, Burkina Faso) \\ ${ }^{3}$ National Center of Vigilance and Health Product (Burkina Faso) \\ ${ }^{4}$ Joseph Ki-Zerbo University of Ouagadougou (Burkina Faso)
}

\begin{abstract}
.
Pharmacovigilance is based on individual case safety reports. Our study is intended to be a contribution to good practices by the quality assessment of individual case safety reports sent to the National Center for Vigilance in Burkina Faso. We carried out a cross-sectional study which concerned individual case safety reports sent to the Center between 2009 and 2014. 302 individual case safety reports forms were identified and the rate of notifications per year and per million inhabitants was 2,9. The sex ratio was 0,83 in favor of women and the average age was 14,3. 320 drugs were listed with a predominance of antimalarials $(37.8 \%)$ and antibiotics (19\%). Adverse reactions were mostly cutaneous-allergic $(37.9 \%)$ and general $(25.2 \%)$. More than half of individual case safety reports were sent by pharmacists $(58.6 \%)$ followed by nurses $(29.5 \%)$ then doctors $(6.6 \%)$. An analysis of the quality of the files according to WHO criteria gave $25.8 \%$ for grade A, $67.2 \%$ for grade $B$ and $7 \%$ for grade $C$. The files were transmitted within 15 days in $54 \%$ cases. The description of the adverse drug reactions was in accordance with WHO ART terminology in 93.5\%. Underreporting is a reality and special attention should be paid to collecting information on adverse drug events.

Keywords: Adverse effects, Drugs, WHO grade, Pharmacovigilance, Burkina Faso.
\end{abstract}

\section{Introduction}

The drug is an active substance capable of causing a modification of the biological activity resulting in the therapeutic effect which is a beneficial and desired effect. Along with this desired therapeutic effect, the drug is likely to cause adverse events [1]. Pharmacovigilance is the activity of monitoring, recording and evaluating as early as possible the adverse effects of drugs based on notifications from healthcare professionals but also from patients [2]. Its operation is based on the individual case safety reports of adverse events that may be caused by drugs. It is essential for spotting new or rare side effects: it is often said to be the cornerstone of pharmacovigilance [3]. Adverse drug reactions are estimated to be a significant cause of death in some countries, ranking between 4 th and 6 th place. The percentage of hospitalizations due to these reactions varies between 10 and $20 \%$. This phenomenon has serious economic repercussions on health care services, and some countries devote as much as 15 to $20 \%$ of their health budget to drug-related problems [4]. The quality is an important characteristic of the notifications collected, the pharmacovigilance system developed must allow the acquisition of sufficient information for the scientific evaluation of the notifications [5].

To date, no study on the quality of individual case safety reports has been carried out in Burkina Faso. The present study aims to assess the quality of individual case safety reports in order to improve the quality of the filling in of notification forms for adverse drug events by professionals in Burkina Faso.

\section{Methodology \\ Study framework}

We carried out the study at the National Center of Vigilance and Health Products (NCVPH). It covered all of the individual case reports sent to the center between 2009 and 2014.

\section{Type and period of study}

Our study is a retrospective descriptive study. The study concerned the pharmacovigilance sheets sent to the NCVHP from 2009 to 2014. The period of January 2015 enabled us to collect data within the NCVPH.

\section{Data collection and processing procedure}

The technique of data collection was to use the information available. Our data consisted of data from the notification forms completed by health professionals and sent to the NCVHP from 2009 to 2014.

An exhaustive sampling of all notifications meeting the inclusion criteria was carried out, for a total of 302 files.

$\square$ Inclusion criteria: all spontaneous notification forms sent to the NCVHP from 2009 to 2014 have been included.

Non-inclusion criteria: notification forms from active surveillance, clinical trials, etc. have not been included.

\section{Ethics and deontology}

A request for authorization to access and use data from the pharmacovigilance database has been sent

\footnotetext{
* Corresponding author: roambanazaire@outlook.fr
} 
to the NCVHP. The pharmacovigilance sheets were analyzed with respect for their confidentiality and anonymity. They have been reclassified in the archives of the NCVHP.

\section{Results}

We identified 302 individual case safety reports sent to the NCVHP between 2009 and 2014, the notification rate was 2.9. The average age of our patients was 14.3 years with extremes of. Patients aged 16 to 60 were the most affected by the side effects. The sex ratio was 0.83 in favor of women (Figure 1, Figure 2).

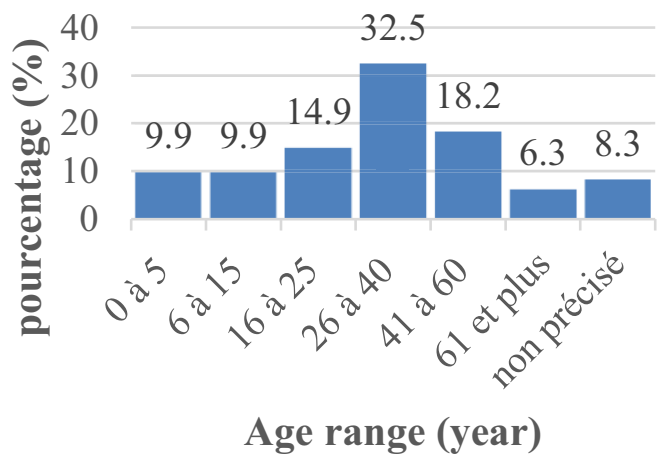

Figure 1: Distribution of patients by age group $(n=302)$

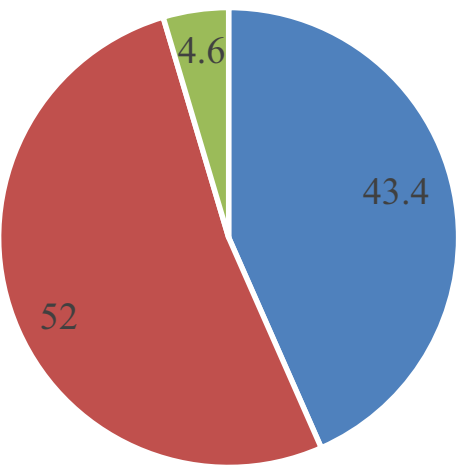

Masculin

- Féminin

" non précisé

Figure 2: Distribution of patients by age group $(n=302)$

The number of drugs or drug combinations that caused an adverse event was 320 (Table I).
Table I: Distribution of drugs according to ATC classification $(n=320)$

\begin{tabular}{|c|c|c|}
\hline $\begin{array}{l}\text { Classification } \\
\text { Anatomique, } \\
\text { Thérapeutique } \\
\text { Chimique } \\
\text { médicaments }\end{array}$ & Effectif & $\begin{array}{l}\text { Pourcentage } \\
(\%)\end{array}$ \\
\hline $\begin{array}{l}\text { A : digestive system and } \\
\text { metabolism }\end{array}$ & 18 & 5,8 \\
\hline $\mathrm{C}$ : cardiovascular system & 14 & 4,3 \\
\hline $\begin{array}{l}\text { G : genito-urinary system } \\
\text { and sex hormones }\end{array}$ & 3 & 0,9 \\
\hline $\begin{array}{ll}\mathrm{H}: \text { systemic } & \text { hormonal } \\
\text { preparations, } & \text { excluding } \\
\text { sex hormones } & \end{array}$ & 2 & 0,6 \\
\hline $\begin{array}{l}\mathrm{J}: \text { anti-infectives for } \\
\text { systemic use }\end{array}$ & 107 & 33,4 \\
\hline $\begin{array}{l}\mathrm{L}: \text { antineoplastics and } \\
\text { immunomodulating } \\
\text { agents }\end{array}$ & 2 & 0,6 \\
\hline $\mathrm{N}$ : the nervous system & 39 & 12,2 \\
\hline $\begin{array}{l}\text { P : pest control products, } \\
\text { insecticides and repellants }\end{array}$ & 135 & 42,2 \\
\hline Total & 320 & 100 \\
\hline
\end{tabular}

In total, the drugs frequently implicated were antimalarials (37.8\%), antibiotics (19\%), ARVs $(10.6 \%)$, analgesics-antipyretics $(6.6 \%)$. Of the 302 notifications 325 symptoms were detected. Their distribution is shown in Table II.

Table II: Distribution of adverse reactions according to their class $(n=325)$

\begin{tabular}{lll}
\hline $\begin{array}{l}\text { Classe système/organe } \\
\text { (SOC) }\end{array}$ & $\begin{array}{l}\text { Effectif } \\
\text { des EIs }\end{array}$ & $\begin{array}{l}\text { Pourcentage } \\
\text { (\%) }\end{array}$ \\
\hline $\begin{array}{l}\text { Blood and lymphatic } \\
\text { system disorders }\end{array}$ & 4 & 1,2 \\
$\begin{array}{l}\text { Cardiac disorders } \\
\text { Ear and labyrinth disorders }\end{array}$ & 7 & 1,2 \\
$\begin{array}{l}\text { Eye disorders } \\
\text { Gastrointestinal disorders }\end{array}$ & 6 & 1,1 \\
$\begin{array}{l}\text { General disorders and } \\
\text { administration }\end{array}$ & 82 & 14,5 \\
$\begin{array}{l}\text { conditions } \\
\text { Hepatobiliary disorders }\end{array}$ & 17 & 5,2 \\
$\begin{array}{l}\text { Nervous system disorders } \\
\text { Psychiatric disorders }\end{array}$ & 4 & 1,2 \\
$\begin{array}{l}\text { Kidney and urinary tract } \\
\text { disorders }\end{array}$ & 15 & 2,8 \\
$\begin{array}{l}\text { Reproductive system and } \\
\text { breast disorders }\end{array}$ & 7 & 2,2 \\
$\begin{array}{l}\text { Skin and subcutaneous } \\
\text { tissue disorders }\end{array}$ & 123 & 37,9 \\
\begin{tabular}{l} 
Total \\
\hline
\end{tabular} & 325 & 100 \\
\hline
\end{tabular}


The most common adverse effects were cutaneousallergic $(37.9 \%)$, systemic $(25.2 \%)$, gastrointestinal $(14.5 \%)$, hepatic $(5.2 \%)$ and renal (4) effects. , $6 \%)$. More than half of the notifications were reported by pharmacists $(177 / 302$ or $58.6 \%)$ followed by nurses $(29,5 \%)$, doctors $(6,6 \%)$ and others practitioners.

Individual case safety reports were sent less than 15 calendar days after notification in $54 \%$ of cases. The quality of the files is presented in Table III.

Table III : Distribution of notifications by WHO grade $(n=302)$

\begin{tabular}{lll}
\hline Grade & Effectif & Pourcentage (\%) \\
\hline A & 78 & 25,8 \\
B & 203 & 67,2 \\
C & 21 & 7 \\
Total & 302 & 100
\end{tabular}

Table IV presents the analysis of the description of adverse reactions in relation to WHO ART terminology.

Table IV: Distribution of compliance of the description of adverse reactions according to WHO ART terminology $(n=325)$

\begin{tabular}{lll}
\hline $\begin{array}{l}\text { WHO ART } \\
\text { Terminology }\end{array}$ & Effectif & $\begin{array}{l}\text { Pourcentage } \\
(\%)\end{array}$ \\
\hline Conforme & 304 & 93,5 \\
Non conforme & 21 & 6,5 \\
Total & 325 & 100,0 \\
\hline
\end{tabular}

\section{Discussion \\ Difficulties of the study}

We were faced with the difficulty of finding the date of receipt of certain notification forms transmitted administratively and in a grouped manner. Indeed, the date of receipt was not systematically indicated on all notices. This could result in probable confusion in determining the number of individual case safety reports per year.

\section{The number of notifications}

A total of 302 individual case safety reports were analyzed in our study. With an average notification rate in our study of 50.3 and by applying the WHO recommendation on the basis of $16,779,207$ inhabitants [6], the notification rate is 2.9. This figure shows real, but not specific, under-reporting in Burkina Faso. "Underreporting is a common problem" [7] in countries. Indeed, the WHO recommends 350 to 700 notifications per million inhabitants per year. In countries with effective pharmacovigilance, it is estimated that less than $10 \%$ of serious effects are declared [8]. This rate of undernotification is evaluated at a rate between 90 to $95 \%$ [9]. In the literature, we found notification rates approaching the results of our study. The study of
Kamgo JM. in Mali had found a hospital underreporting of 2.8 [10].

This under-notification can be explained by several reasons: a lack of awareness of the interest, the workload, the feeling of guilt, the causal link not established, the fear of ridicule, the desire to publish, disinterest [7]. In order to improve notification and data collection mechanisms, the notification of adverse events after marketing authorisation can be encouraged by involving all stakeholders (healthcare professionals, patients). Health authorities should undertake to promote the teaching of pharmacovigilance in the professional training of students in the health professions [11]. Also, field surveys can be carried out with professionals to determine the degree of influence of factors in underreporting.

\section{Characteristics of individual case safety reports Patients}

The most affected age groups in our study were represented by patients aged 16 to 60 years. The sex ratio was 0.83 in favor of the female sex. The pharmacovigilance report of the Morocco anti-poison and pharmacovigilance center (MAPC) in 2005 also showed that patients aged 16 to 60 were the most affected by adverse drug reactions [12]. The sex ratio was 0.28 in favor of the female sex. This can be explained by the special attention given to the care of children and the elderly. This could limit the risk of side effects occurring during treatment.

\section{Drugs}

The most incriminated drug classes were antimalarials (37.8\%), antibiotics $(19 \%)$, ARVs $(10.6 \%)$, analgesics-antipyretics $(6.6 \%)$. This can be explained by the frequency of conditions for which these drugs are indicated. Malaria is the first reason for consultation in Burkina [6]. These patients are more exposed to drugs and therefore likely to manifest adverse reactions. We have different results in the literature probably related to the study setting. Soukho-kaya and col in 2006 in Mali had found that anti-diabetics were responsible for adverse effects in $48.6 \%$ and anti-tuberculosis drugs in $21.3 \%$. Indeed, it was carried out in an internal medicine department which mainly deals with metabolic and endocrine diseases [13]. In the CAPM report, oral contraceptives are the most incriminated (37.5\%) followed by non-steroidal anti-inflammatory drugs $(13 \%)$ and antibiotics (11\%). Antiparasitics have a low rate $(1 \%)[12]$.

In the study of Keita KB. in Mali in 2012, ARVs were the most notified with a rate of $56.3 \%$. They were followed by antibiotics with $31.3 \%$ then nonsteroidal anti-inflammatory drugs $18.8 \%$. There were no antimalarials [14]. This study was carried out within the National Center for Support against Disease and concerned the leprology / animal services, the support and counseling unit and the dermatology service. Drug eruptions are the most frequently encountered side effects and the drugs responsible are mostly ARVs. There are no 
antimalarials probably because of the profile of the patients treated.

It is important to remember that the drug treatment of pathologies requires the use of quality drugs, guaranteed to be effective in their action [15]. A quality defect in a medicine can cause side effects. We advocate strengthening quality control and compliance with the conditions of use to ensure drug safety.

\section{Adverse effects}

The adverse reactions described have been classified according to System Organ Classes (SOC) terminology. The most common side effects were skin allergic effects $(37.9 \%)$, systemic effects $(25.2 \%)$ and gastrointestinal effects $(14.5 \%)$. The National Reference Center for Pharmacovigilance (NRCP) in Mali also found a predominance of skin effects with $38.9 \%$ in 2011 [16]. Soukho-kaya et al had shown a predominance of neurological (53.2\%) and digestive (29.8\%) effects. The CAPM report in 2005 also showed that the majority of the effects were cutaneous (27\%), gastrointestinal (18\%) and neurological $16.5 \%$ ). One of the limitations of premarketing studies is the fact that they cannot detect all of the adverse effects of a drug in terms of their frequency and nature [17]. Indeed, during laboratory tests, certain effects may escape the experimenter given the constitution, physiology but also the difficulty of qualifying or apprehending the effect in animals. An effective and permanent integration of pharmacovigilance in the diagnosis and treatment of pathologies is desirable. It could contribute to the prevention of adverse effects, especially avoidable, and to better safety in the use of medicines.

\section{Notifiers}

Pharmacists reported more individual case safety reports with a rate of $58.6 \%$. This is due to the fact that in the profile of notifiers, in particular general practitioners and general pharmacists, we have included interns in medicine or pharmacy. The pharmacovigilance module is taught in the 5th year of pharmacy and the notification of adverse drug events is one of the internship objectives of clinical pharmacy. This may show the students' interest in the pharmacovigilance issue and explain the high rate of notifications from pharmacists. A study by Baniasadi S. et al in Ghana in 2010 over 12 months showed that the participation of clinical pharmacists greatly contributed to improving the notification rate [18]. Khan et al had shown in a study in Pakistan that pharmacy students had more knowledge and skills in their ability to report side effects than medical students [19].

\section{Deadline for submitting adverse effects}

Notifications must be sent to a pharmacovigilance structure within 15 days of the event being detected. In our study, we considered the NVCHP as the reference structure. Overall, 54\% of notifications were sent in a timely manner. Cases of indefinite transmission time are linked to the impossibility of finding the slips of the forms received at the center since the dates of receipt are not mentioned on all the forms. Is the transmission of the forms the result of negligence on the part of professionals or of a slow administrative procedure? A field survey could provide information on the factors that influence the transmission delay.

\section{WHO quality of individual case safety report}

Overall, the quality of individual case safety reports is satisfactory. Good quality notifications represented $25.8 \%$ for grade A and $67.2 \%$ for grade B. Grade C notifications (unusable files) only represented $7 \%$ in our study. Kamgo JM. in mali with a different approach had found $55.2 \%$ good quality infill. The methodology used consisted in determining the filling rate of the items of the notification forms. The OMS method takes into account not only filling in but also the need or not to supplement the information subsequently by contacting the notifier. Grade A and $B$ notifications have been increasing since 2009. The low rate in 2012 can be explained by an error of assessment on the year of notification. In fact, the notification forms were arranged by year. There are records for which the year of notification is not explicit. According to Tebaa A, the qualification of the health professional can influence the quality of the declaration [20].

The improvement in quality is explained by an increasingly effective knowledge of individual case reports through periodic training of health professionals. These trainings show participants the need to report adverse drug reactions detected in daily practice. The solutions to further improve the quality of notifications are the same for undernotification. Indeed, improving the notification rate implies an incentive for quality notifications.

Conformity of the description of adverse effetcs to WHO-ART terminology

The description of the adverse drug reactions was consistent in $93.54 \%$ of the effects described, i.e. the terms used in the description of the adverse reaction correspond to the terms adopted by WHOART. The non-compliant cases were mainly related to the absence of the adverse event described.

\section{Conclusion}

Pharmacovigilance in Burkina Faso is essentially based on the individual case safety reports of suspected adverse reactions by health professionals to pharmacovigilance structures. This study consisted in the quality assessement of the information collected through the pharmacovigilance sheets.

Adverse effects were mainly cutaneous-allergic (37.9\%), general $(25.2 \%)$, gastrointestinal (14.5\%). The drugs in question belong to the classes of antimalarials (37.8\%), antibiotics (19\%) and ARVs $(10.6 \%)$. Pharmacists made the most notifications with $58.6 \%$ followed by nurses $(29.5 \%)$. The majority of inividual case reports were of good quality and the percentage of notifications from pharmacists was the highest. This study can contribute to the feedback of information to health 
professionals on the quality of notifications made in the practical field. The quality of spontaneous notifications should not be neglected because of the importance of pharmacovigilance in the life of the medicinal product.

\section{References}

1. S. Elmezdali. Pharmacovigilance and its challenges. International and Moroccan pharmacovigilance systems. Edition universitaires européennes. 106p (2011)

2. Lexique de pharmacovigilance. University of Bordeaux website www.pharmacologie.ubordeaux2.fr Retrieved Décembre 10, 2014

3. A. Alvarez-Requejo, A. Carvajal, B. Bégaud, Y. Moride, T. Vega, LH. Arias. Under-reporting of adverse drug reactions. Estimate based on a spontaneous reporting scheme and a sentinel system. Eur J Clin Pharmacol ; 54, 483-488 (1998)

4. OMS. Drug safety. Checklist for a national strategy to ensure the safety and appropriate use of drugs. $3 p$

5. European Medecines Agency. Guidelines on good Pharmacovigilance practices module VI. Rev 1 2014 : [consulté le 06/12/2015] Available at http : www.emea.europa.eu

6. MS SG DGISS : Statistical Yearbook 2012 : Ouagadougou ; 237p (2013)

7. UMC. Safety monitoring of medicinal products. Guidelines for setting up and running a Pharmacovigilance Center ; 32p (2000)

8. SR. Bencheickh. General information on spontaneous notification. French inter-country pharmacovigilance course : Available at : http://www.who.int/medicines/areas/quality_safety/s afety_efficacy/trainingcourses/4notification_spontan ee.pdf?ua=1 Retrieved march 2014] (2008)

9. J. Montastruc, A. Sommet, I. Lacroix and al. Pharmacovigilance for evaluating adverse drug reactions: value, organization, and methods. Joint Bone Spine. 6 (2006)
10. JM. Kamgo. Contribution to the establishment of a pharmacovigilance system at the $\mathrm{G}$ point $\mathrm{CHU}$ [Pharmacy thesis]. University of Bamako, $\mathrm{N}^{\circ} \mathbf{0 1}$ : 163p (2010)

11. International society of drug bulletins. Berlin Declaration on Pharmacovigilance ; Rev. Prescrire ; 25 (2005)

12. CAPM. Annual report, Morocco : $2005: 39 p$

13. A. Soukho-kaya, DK. Minta, A. Konaté and al. Adverse drug reactions in the internal medicine department at the G point CHU. Mali médical : XXV, 3 (2010)

14. KB. Keita. Descriptive study of the notification of adverse events of notifications to the national support center for disease control / vaccine development center. Mali [Medical thesis]. Bamako University of Science and Technology; 76p (2012)

15. IP. Guissou. Therapeutic quality of drugs. UE qualitology; master's degree in pharmacotherapeutics;. Ouagadougou, Burkina faso ; (2015)

16. SR. Bencheikh. General information on spontaneous notification. In DPM : Workshop seminar on the establishment of a pharmacovigilance system in Mali ; Mali, Bamako ; (2009)

17. K. Benichou. Practical guide to pharmacovigilance, paris, ed pradel, (1996)

18. S. Baniasadi, M. Habibi, R. Haghgoo and al. Increasing the number of adverse drug reactions reporting: the role of clinical pharmacy residents. Iran J Pharm Res ; 13, 291-297 (2014)

19. MU. Khan, A. Ahmad, A. Ejaz and al. Comparison of the knowledge, attitudes, and perception of barriers regarding adverse drug reaction reporting between pharmacy and medical students in Pakistan. J Educ Eval Health Prof ; 12, (2015)

20. A. Tebaa. Assessment of the quality of individual case safety report. French inter-country pharmacovigilance course. Rabat ; 37p (2008) 